\title{
Intersectionality and the Interpretation of Past Pandemics
}

\author{
Samantha L. Yaussya \\ ${ }^{a}$ Department of Sociology and Anthropology, Utah State University, Logan, UT \\ Correspondence to: Samantha L. Yaussy, Department of Sociology, Social Work, and Anthropology, \\ Utah State University, 0730 Old Main Hill, Utah State University, Logan, Utah 84322-0730 \\ E-mail: SLYaussy@gmail.com
}

ABSTRACT Intersectionality refers to the potential for multiple axes of identity to overlap and interact within a single individual, whose lived experiences are further affected by structural forms of oppression that are perpetuated within their society. Intersectionality has been adapted by a variety of social science disciplines exploring the negative effects of multiple marginalization and systemic inequality in living populations, but remarkably few intersectional studies of health or pandemics in the past have been produced in bioarchaeology. Bioarchaeologists, specifically, are uniquely positioned to contribute to interdisciplinary discourse by expanding the contextual and temporal purviews of intersectionality scholarship, which currently focuses primarily on living populations from Western, industrialized contexts. The purpose of this review is to encourage and facilitate intersectionality research within bioarchaeology. To accomplish this goal, the article is divided into three sections: the first section provides a general overview of intersectionality, the second section discusses examples of intersectional scholarship from related disciplines that address health disparities and modern pandemics, and the third section considers the ways in which bioarchaeologists might integrate intersectionality in our empirical research on health and disease in the past. Given the potentially daunting task of using bioarchaeological data to investigate intersectionality and health in the past, the third section also highlights three quantitative methodologies that intersectionality scholars have used to investigate the independent, additive effects of individual social identities as well as the multiplicative effects of those same identities as they operate in conjunction with each other to produce patterns of health outcomes in living populations.

Keywords: bioarchaeology; paleoepidemiology; quantitative methods

Intersectionality-a concept developed to address the multiple, interacting identities that exist within a single individual and the systems of power and inequality that influence those identities-developed within Black feminist scholarship and has since been adapted by a variety of scholarly disciplines. Within the past two decades, the disciplines of sociology, public health, and epidemiology have incorporated intersectionality into their frameworks and methodologies to investigate how multiple social categories intersect and interact with structural factors and processes to produce disparities in health within and between human populations. In contrast, anthropological studies of health-particularly bioarchaeological studies of health in the past-have only recently begun explicitly referencing intersectionality and exploring how it can be leveraged to better understand the experiences and health outcomes of people in a variety of cultural contexts.

The purpose of this review is to contribute to future paleopathological and paleoepidemiological research by presenting a basic overview of the aims and concerns of intersectionality, its use in the social sciences by researchers studying health disparities in modern populations, and its potential as a theoretical framework or methodological approach in bioarchaeological 
studies of pandemics in the past. Consequently, this article is divided into three broad sections corresponding to those goals. The first section addresses the origins and development of intersectionality within Black feminist scholarship and activism, as well as how the concept of intersectionality has been critiqued and revised within the social sciences. The second section examines examples of intersectional research produced in social science disciplines adjacent to bioarchaeology, including sociology, public health, and epidemiology. Particularly, the second section aims to provide models of how other scholars have incorporated the concept of intersectionality into their research frameworks to better understand the production and maintenance of health disparities in modern populations. Finally, the third section addresses the potential for bioarchaeological studies to contribute to the growing body of literature addressing questions about intersectionality, identity, structural inequality, and the generation and perpetuation of health disparities across time, space, and cultural contexts. To that end, the third section also introduces analytical methodologies employed in quantitative studies of health produced by other social science disciplines, and it considers the applicability of those quantitative methodologies to the bioarchaeological study of health disparities and pandemics in the past.

\section{The Origins and Development of Intersectionality}

The term intersectionality references the critical insight that categories of social difference and identity (such as race, class, and gender) operate not as mutually exclusive entities but as reciprocally constructed phenomena that interact with forms of systemic oppression (such as racism, classism, and sexism) (Collins 2015). As a result, individuals simultaneously experience multiple overlapping identities and social statuses that contribute to their lived experiences. This acknowledgment of social categories as mutually constitutive and interdependent contrasts sharply with conventional studies of social inequality and marginalization that treat categories of social difference and identity as unidimensional, mutually exclusive, and independent of overarching power structures (Bowleg 2012; Cole 2009).

Legal scholar and critical race theorist Kimberlé Crenshaw $(1989,1991)$ is credited with coining the term intersectionality to describe the lived experiences of Black women who disproportionately bear the negative effects of their individual identities and the macrolevel processes of racism, sexism, and classism relative to other social groups. Particularly, Crenshaw examined how antidiscrimination law, feminist theory, and antiracist politics have disregarded the distinctive experiences of women of color, thereby further marginalizing them in settings traditionally understood to be liberating and progressive. In court cases involving discrimination on the basis of race, the focus is on sex- or class-privileged Black people (i.e., wealthy Black men). Likewise, in sex discrimination cases, discrimination is viewed in terms of race- and class-privileged women (i.e., wealthy White women). As a result, disadvantage is conceptualized as occurring along a single categorical axis, limiting the investigation of race and sex discrimination to otherwise privileged members of the relevant group. Similarly, feminist and antiracist discourses fixate on the experiences of White women and Black men, respectively, and fail to consider the unique subjugation faced by women of color (Crenshaw 1989).

Although Crenshaw's use of the term was new, the concept of multiple, intersecting axes of inequality was articulated decades earlier by Black scholar-activists. Crenshaw herself cites Sojourner Truth as an early proponent of intersectionality in her 1851 speech "Ain't I a Woman?" which exposed the contradiction between stereotypical images of "womanhood" and the experiences of Black women. In the late twentieth century, the Combahee River Collective, a Black feminist lesbian group, would echo Truth's frustrations about feminist assessments of subordination and discrimination that ignored the interrelated axes of gender, race, class, and sexuality (Combahee River Collective 1977). Throughout the 1980s, Latina and African American women in academia (e.g., Anzaldúa 1987; Davis 1983; hooks 1981; King 1988; Lorde 1984) further problematized unilateral conceptions of race, class, gender, and sexuality and contributed an element of activism to intellectual discourse that is prevalent in modern intersectional scholarship (Collins 2015).

Since its development by Black feminist scholars and activists, intersectionality has influenced scholarship in a variety of fields and challenged the idea of a single, fixed social hierarchy. Whereas previous investigations of social inequality treated identity categories (such as race, class, or gender) as independent and mutually exclusive entities, intersectionality references the critical insight that those categories of social difference and sameness are "reciprocally constructing phenomena that in turn shape complex social inequalities" (Collins 2015:2). One area of tension regarding intersectionality is its variable and inconsistent conceptualization in the fields in which it is applied. Intersectionality has been conceived of as a perspective, a concept, an idea, a theory, a nodal point for feminist theoretical engagement, a theoretical framework, a heuristic device, a knowledge project, a methodological approach or type of analysis, a research paradigm, an analytical framework, and even a type of data 
(Collins 2015). The confusion and frustration generated by the definitional ambiguity of intersectionality has led some scholars to call for a more clearly defined and universally applicable definition (Verloo 2006). Still others have argued that intersectionality could be better employed by scholars across disciplinary boundaries if it were accompanied by clear-cut methodological guidelines for its application (McCall 2005). Naturally, these arguments reflect a broad concern on the part of scholars who are interested in intersectionality but are unsure how to productively apply it in their own research. However, other scholars contend that the value of intersectionality lies not in its narrow conceptualization or clearly outlined strategies for operationalization but in its breadth, its lack of precision, and its lack of analytical or theoretical specifications (Collins 2015). In this view, intersectionality's worth as a theory or framework is the fact that it "initiates a process of discovery" and "stimulates our creativity in looking for new and often unorthodox ways of doing feminist analysis" (Davis 2009:79).

Despite being criticized for lacking clearly demarcated analytical strategies or explicitly defined theoretical objectives, intersectionality has been adapted, engaged, and applied in a number of disciplines exploring a great variety of subject areas. The array of identity categories and axes of inequality examined by intersectionality scholars include race, gender, class, educational attainment, relationship status, religion, migrant status, parenthood, sexuality, gender identity, nationality, ability status, Indigeneity, and disease status, to name a few (Springer et al. 2012). In the face of such wide-ranging topical applicability, many scholars are overwhelmed by the methodological complexity of investigating an endless list of potentially significant identity categories and structural inequalities. However, intersectionality explicitly recognizes that the importance of a given identity or systemic force is grounded in the historical and contextual conditions of the population being studied (Christensen and Jensen 2012; Hancock 2007). As a result, which categories are selected and how many categories and intersections are examined are strategic choices made by the investigators. In other words, intersectionality scholars are not obligated to study every category or capture the full extent of the diversity that exists in a given population. Instead, researchers-both qualitative and quantitative-should consider which intersections matter the most for the research question being asked and the populations or contexts being studied, then focus on the categories or intersections that will likely be most salient given the focus of the research project. No one project can expose every outcome of every intersection. Rather, intersectional scholars seek to creatively design their research in such a way that they explicitly consider how simple additive categories may not fully uncover the consequences of the categories and processes of interest (Misra et al. 2020).

Importantly, the question of which categories should be prioritized by intersectionality research is not solely a methodological concern but a theoretical one as well. Given its roots in activism and social justice movements, intersectionality understandably operates as a form of critical praxis aimed at challenging existing dynamics of power, privilege, and oppression (Collins 2015; Moradi and Grzanka 2017). As such, intersectionality research has often prioritized the study of the perspectives and experiences of historically oppressed and multiply marginalized subjects. However, as other scholars have argued, a full engagement of intersectionality necessitates a critical analysis of privilege as well as marginalization, as it is often through structures of power and privilege that hegemonic systems of oppression are maintained (Cole 2009; Moradi and Grzanka 2017). Furthermore, studies that investigate the causes and consequences of multiple identities negotiated within a particular cultural and historical context have the opportunity to foreground the positive, resilient, and empowering aspects of heterogenous identities (Werbner 2013), as well as consider the ways in which some identities may exist in conflict and thus be differentially expressed or experienced in a given sociocultural context (Sengupta 2006). In this view, intersectionality research should endeavor to avoid narrowly fixating on a subset of intersections (i.e., the multiply disadvantaged) or implying that intersectionality only applies to some people, subjects, or intersections at the expense of others, because such a decision could limit the breadth and productivity of intersectional feminist scholarship (Bauer 2014; Hancock 2007; Moradi 2017; Moradi and Grzanka 2017).

\section{Intersectional Approaches and Applications}

Intersectionality has been effectively employed in studies of living populations in a variety of disciplines, including education (Bhopal 2020; Tefera et al. 2018), psychology (Cole 2009; Mitchell et al. 2014; Purdie-Vaughns and Eibach 2008), philosophy (Walby 2007), political science (Hancock 2007), criminology (Paik 2017), sociology (Di Stasio and Larsen 2020; Watkins-Hayes 2014), anthropology (JacksonBest 2016; Jackson-Best and Edwards 2018), and medicine (Baig et al. 2016; Tan et al. 2016). The breadth of research questions and objectives pursued in intersectionality scholarship lends support to its value within the social sciences and encourages other scholars to consider its applicability in their own research 
projects. The sections below specifically focus on intersectional approaches employed by scholars tackling research questions tangential to those in paleopathology, paleoepidemiology, and bioarchaeology more generally. Importantly, the overview of intersectional research presented below is far from comprehensive. Rather, it provides a limited set of examples of successful intersectional studies of health in living populations with the goal of elucidating how an intersectional investigation of past pandemics is readily achievable with the data and expertise already leveraged in our field.

\section{Sociology and anthropology}

Intersectional research in sociology has contributed at least two vantage points from which social science researchers can investigate the relationships among individual identities and systemic forms of advantage and oppression and measure the outcomes of those interactions (Choo and Ferree 2010; Jones et al. 2013; McCall 2005). At the "intracategorical" level of analysis, researchers focus solely on the experiences and perspectives of a single marginalized group within a particular context (McCall 2005). For example, Wingfield's (2009) study of minority men in the culturally feminized field of nursing reveals variation in the experiences of Black men nurses. Although previous research identified a "glass escalator" effect that disproportionately benefited men in historically gendersegregated occupations like nursing (Williams 1995), Wingfield (2009) detects a racialization of the "glass escalator" concept that negatively influences the advancement of minority men in their nursing careers. By focusing on a single disadvantaged group within a specific social setting, sociologists employing the "intracategorical" approach are able to highlight the experiences of individuals at a neglected or understudied intersection. This emphasis on a particular social group underscores the heterogeneity that exists within a given group or context and stresses the concurrent constitution of multiple statuses in any intersectional domain.

In contrast, an "intercategorical" approach examines the transformations and consequences that occur when multiple statuses or identity categories meet (Choo and Ferree 2010; McCall 2005). In this approach to intersectionality, the goal is to examine patterns of interactions between two or more social categories, rather than the outcomes produced at a single intersection of interest. For instance, research by Pager (2003) suggests that the employment opportunities in entry-level jobs for Black men with a felony record differ dramatically from those of White men in similar circumstances. In this case, the identity category of race is capable of exerting its own effect on employment chances while simultaneously producing a separate interaction effect with felony status that can differentially influence employment chances for White and Black men.

Given its focus on the complex relationships that exist within and across social categories-rather than on the outcomes and experiences associated with a particular social group - the intercategorical approach to intersectionality is analytically more complex compared to the intracategorical approach. For example, a study of gender and class necessitates the assumption of distinct gender categories (e.g., men and women) that can then be compared systematically to class categories (e.g., lower, middle, and upper), thus generating six intersectional categories of analysis. A third axis of identity, such as race (e.g., Black and White), would further expand the list of categories being analyzed, such that a consideration of the relationships among three axes of identity becomes a comparative study of 12 separate domains. However, as sociological research demonstrates (e.g., McCall 2001), the analytical complexity of the intercategorical approach need not be daunting to anthropologists and other social scientists interested in employing a quantitative intersectional framework. As discussed below, hierarchical models can evaluate both independent associations between two variables and higherorder interactions among three or more variables, allowing investigators to assess the effects of a single social or biological category as well as the more complex, intersectional domains of interest.

Anthropological methodologies and perspectives emphasize a holistic understanding of human diversity and have a great deal to contribute to intersectional scholarship. Particularly, the understandings that inequalities and power structures are "historically contingent and cross-culturally specific" (Gkiouleka et al. 2018:93) and that identities and their meanings vary across space and time (Bowleg 2012; Chan and Howard 2018; Collins and Bilge 2016; Giritli Nygren and Olofsson 2014; Iyer et al. 2008) seem to invite anthropological investigation and interpretation. In terms of potential contributions to intersectional studies of health, anthropologists are ideally situated to investigate the historical production and maintenance of structural inequalities, the variable consequences of and responses to marginalization cross-culturally, and the temporal variation in outcomes associated with intersecting social identities. However, despite this opportunity to engage in transdisciplinary conversations about the generation and outcomes of intersectional domains, anthropologists interested in studying health are disproportionately underrepresented in the intersectionality literature. Excepting the notable 
contributions of anthropologists like Khiara Bridges (2011) and Fatimah Jackson-Best (2016), intersectional research on health and health outcomes-especially research of the quantitative variety-has been largely produced by other social science disciplines and has remained focused on high-income, industrialized populations like the United States and United Kingdom. Anthropological research could provide key insights regarding the variation that exists (and has existed) in identity categories and the experiences and health outcomes of the marginalized throughout human history and thus contribute to intersectional scholarship by expanding its contextual and temporal purviews.

The relative dearth of intersectional research on health within anthropology may be explained by inconsistent use of the term intersectional or intersectionality in the discipline. That is, anthropologists are producing research on health in the past and present that can be considered intersectional and are engaging with intersectionality; they are simply not explicitly using the term. For example, in her pioneering work on "ethnogenetic layering", Jackson (2003, 2004, 2008) describes the importance of recognizing genetic and nongenetic factors that interact in complex ways within populations to produce the variable health and disease outcomes observed in human groups. Ethnogenetic layering acknowledges the cultural and historical elements specific to microethnic groups, which may be overlooked by studies of health and disease that focus solely on macroethnic (or racial) groups (Jackson 2004). Thus, ethnogenetic layering exposes the unique domains that exist within larger, less homogeneous analytical categories, and it exemplifies the implicitly intersectional research questions being pursued by anthropologists studying health in human populations.

As in other disciplines grappling with the complexities of theoretical perspectives and frameworks that critically examine the intersecting axes of power that influence patterns of privilege and marginalization, indoctrination in terms of language, methods, or conventions need not be a precondition to produce meaningful intersectional research (Cho et al. 2013). However, if anthropologists studying health disparities are interested in engaging intersectionality in their research and contributing to interdisciplinary intersectional discourse, explicit use of the term will be necessary to integrate anthropological studies of health with the work of social scientists from other disciplines. Citing the relevant intersectional literature (e.g., Crenshaw 1989, 1991) and unambiguously connecting anthropological data to previous intersectionality research will make the nuanced perspectives and findings of anthropological studies accessible for scholars in other disciplines. Introducing new iterations of intersectionality, such as intersectional studies of health in non-Western, nonindustrialized contexts or intersectional studies of health in past populations, will require anthropologists to enter the discussion in a visible, purposeful manner. However, as has already been recognized by scholars in other fields, the expansion of intersectional analysis across multiple sites, contexts, and time periods is a worthy endeavor that will fruitfully broaden intersectionality's discursive terrain (Patil 2013).

Alternatively, some anthropologists who might otherwise engage with intersectionality may be mystified by the methodological demands of applying intersectional analyses in quantitative studies. Indeed, many scholars associate intersectionality with qualitative research approaches, because ethnographic approaches, interviews, and participatory action research methods appear to be intrinsically aligned with complex and dynamic understandings of socially constructed dimensions of difference (Hunting 2014; Misra et al. 2020). Understandably, potential practitioners of intersectionality may balk at the idea of integrating relational thinking into empirical research studies. In this respect, anthropologists are not alone (Collins 2015; McCall 2005), and intersectional scholarship has been criticized for lacking a definitive and diverse methodological approach (Nash 2008). However, in response to these methodological critiques and concerns, there has been an outpouring of support from quantitative scholars in a number of disciplines who have employed intersectionality-informed empirical analyses of health outcomes and disparities (e.g., Bowleg 2008; Covarrubias 2011; Dubrow 2008; Hancock 2007, 2019; Hargrove 2018; Jang 2018; Merlo 2018; Veenstra 2011). Further, as Spierings (2012:337) notes, "Existing (basic) methods and models are already sufficient for tackling many empirical questions," including intersectional questions. As the "Quantitative intersectional methods" section below demonstrates, an empirical, intersectional anthropology of health in the past is achievable with bioarchaeological and paleopathological data and with statistical methodologies already in use in the field.

\section{Public health and epidemiology}

In recent years, intersectionality has been adapted by epidemiologists and public health scholars in studies of living people in a number of contexts. These research projects offer examples of research questions and topics of interest that could foster similar research in paleoepidemiology and paleopathology. For example, some of the first publications leveraging intersectionality in studies of health focused on the HIV/AIDS 
epidemic, particularly in nations like the United States, Canada, and the United Kingdom (Collins et al. 2008; Dworkin 2005; Watkins-Hayes 2014). A study by Doyal (2009) of HIV-positive Black African migrants in London underscores the importance of considering intersectional domains or positions, rather than a single axis of inequality (e.g., gender), when conducting health research (especially if it informs policy). For instance, the HIV/AIDS-related stigmatization and discrimination experienced by gay and bisexual men were primarily linked to societal ideas of sexual deviance, whereas the stigmatization experienced by heterosexual men was predominantly associated with their lack of financial resources, limited employment opportunities, or perceived loss of social power. Similar variations in the lived experiences of different intersectional positions were found in the availability and inclusivity of sources of social support (e.g., religion or spirituality) and organized support groups available to heterosexual and gay or bisexual African migrants in the United Kingdom (Doyal 2009). Other studies have emphasized how intersecting axes of social inequality are causing the HIV/AIDS epidemic to disproportionately affect Black men who have sex with other men (Millett et al. 2012). For example, in their study on the experiences of young Black gay men in California, Arnold and colleagues (2014) noted that stigma, homophobia, and racism intersected to influence patterns of sexual risk behavior, willingness to seek out HIV testing or care, treatment adherence, and willingness to disclose HIV status to sexual partners. Typical sources of support in Black communities facing racism on a societal level-such as the support offered by an individual's family or church-are often rescinded in the face of homophobia and stigma related to HIV status. These intersecting axes of stigmatization and marginalization alter the experiences, decisions, and health outcomes of young Black gay men who are HIV positive relative to their counterparts occupying other intersectional positions, such as White men who do not self-identify as gay (the experiences of transgender people with HIV/AIDS, Black or white, were not explicitly addressed in the above studies).

Another growing area of research in intersectional studies of health focuses on the intersecting axes of social inequality that are generating disparities in infection risk, disease burden, and outcomes among racial and ethnic minorities, women, and undocumented workers in the COVID-19 pandemic (Bowleg 2020; Laster Pirtle 2020). In the United States, structural and institutional racism are increasing risk of COVID-19 exposure and reducing protective barriers to exposure among African American, Latina, and Native American women, increasing infection risk and risks of mortality among these groups (Ryan and El Ayadi 2020). An intersectional perspective enables social epidemiologists to consider how intersecting identity categories and systemic inequalities are affecting sexual and gender minorities to increase the risks associated with COVID-19, including preexisting health conditions (e.g., higher asthma prevalence), economic inequity (e.g., more likely to have experienced loss of income or employment), occupation, and stigmatization (Gibb et al. 2020; Wenham et al. 2020).

A third developing area of research in public health involves investigating the effects of intersecting social and demographic factors on health outcomes associated with tuberculosis. Epidemiologists have long realized that tuberculosis transmission, treatment initiation, treatment adherence, and disease outcomes are associated with class, race/ethnicity, age, and sex (de Seixas Maciel et al. 2018; Muture et al. 2011; Kigozi et al. 2017; Liew et al. 2015; Tola et al. 2015), but they have only recently begun investigating the intersections of these factors in living populations. A study of tuberculosis patients in Mamelodi, South Africa, found that patients were less likely to continue treatment for the disease if they were "physically, socially, and institutionally 'out of place"” (Ilunga et al. 2020:5). Specifically, patients were more likely to stop seeking treatment if they were older (i.e., $>60$ years of age), at risk of poverty (i.e., on the threshold of being "poor"), and had no South African identification documents (i.e., migrants) (Ilunga et al. 2020). These factors, when viewed through an intersectional lens, generate a much richer picture of the social and structural factors that influence tuberculosis outcomes. Although each factor exerts an independent effect on health outcomes, it is only from an intersectional perspective that the patterns of morbidity and mortality observed by public health scholars can be fully understood.

Intersectionality-informed research on health inequalities has most frequently investigated the dimensions of race, gender, and sexuality; the intersections of those identities; and how institutions shape individuals' positioning and experiences, including their health outcomes (Gkiouleka et al. 2018). However, newer studies are expanding the identity categories and institutional factors considered pertinent to health outcomes and therefore broadening the set of intersections deemed relevant in studies of health in living populations. For example, following a call for more intersectional studies of immigrant health (Viruell-Fuentes et al. 2012), Freedman (2016) explored the risks of sexual and gender-based violence against refugees attempting to reach destinations in the European Union. The findings of the study indicated vulnerabilities specific to women refugees, such as sexual coercion from smugglers in exchange for safe 
passage, that were not observed among men refugees (Freedman 2016). Importantly, studies of migrant or immigrant status and health outcomes like sex-based violence are not only accessible to social science researchers exploring these contexts in living populations. Using isotopic and ancient DNA evidence, bioarchaeological studies are also capable of examining how migrant status intersected with other social categories to influence lived experiences and health outcomes in the past, thus engaging in a dialogue with scholars performing studies on living populations to understand variation in these processes and outcomes in the past and present. For example, data on strontium, oxygen, and lead isotopes have been used to track mobility and identify migrants in Roman Britain over the past two decades (e.g., Chenery et al. 2010; Leach et al. 2009; Montgomery 2002; Müldner et al. 2011; Shaw et al. 2016). When thoughtfully combined with sex estimates, assessments of trauma (to access patterns of interpersonal violence or accidental injury), or disease status, bioarchaeological data on mobility and migration could be integrated into an intersectional framework to study complex patterns of health outcomes in the past.

\section{Bioarchaeology and Intersectionality}

The discipline of bioarchaeology is uniquely positioned to provide temporal depth to intersectionality research on health and disease through the analysis of human skeletal remains and their mortuary contexts. As mentioned above, anthropologists, in general, are capable of providing key insights about cross-cultural and temporal variation in the types and numbers of individual-level categories of social difference, the effects or consequences of various combinations of advantage and disadvantage, and how different aspects of identity may be leveraged in diverse contexts to engender resilience. Bioarchaeologists, in particular, can contribute to understandings about the production and maintenance of oppressive forces and processes at the structural level and challenge the narrative of universal identity categories and outcomes through the material evidence and diverse contextual information contained in the bioarchaeological record (Geller 2017). By using information that is inaccessible through any means other than the analysis of human skeletal remains, bioarchaeologists can shed light on how historically generated patterns of inequality and systems of oppression can be dismantled to the benefit of living populations.

Despite having a unique perspective on the existence of multiple, co-occurring identities and the impacts of those intersecting identities on lived experiences and health outcomes in a variety of contexts, few bioarchaeological studies have explicitly engaged with the concept of intersectionality, and to date, none have attempted an intersectional analysis of one or more pandemics in the past. In some cases, substantive application of intersectionality in bioarchaeology has been hindered by the diminutive sample sizes typical of bioarchaeological studies. For example, in her study examining the paleopathological and isotopic evidence for variation in the lived experience of enslavement in antebellum North Carolina, Dent (2017) recognizes that the interindividual variation in health outcomes identified by her analyses would be further elucidated by intersectional approaches. However, as is true of many bioarchaeological studies, the cemetery population analyzed in Dent's study consisted of fewer than 20 individuals, making intersectional analyses of multiple biosocial categories difficult. Although other disciplines grapple with the limitations of small sample sizes when conducting statistical analyses meant to identify interaction terms as measurable products of intersecting variables (Scott and Siltanen 2017), large sample sizes are particularly rare in bioarchaeological studies. Archaeological sites rarely produce sufficiently sized skeletal samples that can be divided into meaningful categories of identity and subsequently scrutinized for patterns. Instead, many bioarchaeological studies pool data across sites or temporal periods to assemble a large enough sample to detect patterns and make meaningful interpretations. For instance, Geller (2017) acknowledges the value of intersectional analyses and interpretations in bioarchaeological studies but does not apply intersectionality to her own data on Classic period (ca. 250 B.C. to 900 A.D.) Maya burials given that her samples were drawn from multiple different sites in northwestern Belize. Although the limitations of bioarchaeological data pose challenges to intersectional studies that undoubtedly require creative solutions in terms of research design and analysis, this constraint should not thwart potential practitioners in our field from employing an intersectional approach to the fullest extent possible.

In the past several years, scholars have increasingly recognized intersectionality as a viable approach in bioarchaeological studies of health and identity in the past. In bioarchaeology, intersectionality and other relational approaches promote the examination of pervasive systems of social stratification (such as gender) and the effects these systems of inequality have in terms of access to resources, which ultimately affects patterns of health and disease (Zuckerman and Crandall 2019). One bioarchaeological study that incorporates intersectionality into its study design is a study by Byrnes (2017) of the interactions among various 
social categories and impairment and disability. Byrnes examines a skeletal sample excavated from the site of the Erie County Poorhouse in Buffalo, New York, which includes 207 adult individuals who exhibit osteological evidence of physically impairing injuries. Evidence of hard tissue traumas (such as fractures) and some soft tissue traumas (such as dislocations) was used to estimate the degree of impairment of each individual, and the resultant impairment classes (from "none" to "very severe") were then compared to sex and age at death categories in an analytical framework that is remarkably similar to the intercategorical approach used by sociologists. Generally, results indicated that males of low socioeconomic status were more likely to exhibit a greater number and greater severity of traumatic injuries, which is likely related to the hazards posed by the occupations available to the unskilled laborers residing in the poorhouse. By combining evidence gathered from the skeletal data with evidence from documentary sources on the demographics of the inmates of the poorhouse, Byrnes (2017) concludes that ethnicity also contributed to the lived experiences and health outcomes endured by the inhabitants of the poorhouse. Specifically, the intersection of gender, ethnicity, socioeconomic status, and age likely influenced employment opportunities, access to resources, social mobility, and degree of impairment experienced by the poor in late eighteenth- and early nineteenthcentury New York.

Two additional intersectional studies in bioarchaeology were contributed by Torres-Rouff and Knudson (2017) and Knudson and colleagues (2020). In their first publication, Torres-Rouff and Knudson (2017) employ an integrated, multiscalar approach to examine the immutable and mutable aspects of social identity in the San Pedro de Atacama region of northern Chile. The data assessed by Torres-Rouff and Knudson include cranial metric and nonmetric traits (to access biological relationships or patterns of genetic relatedness at the population level), radiogenic strontium and stable oxygen isotope data (to infer geographic origins and residential mobility at the individual level), estimates of physiological age and biological sex (to access social age and gender at the individual level), type and degree of cranial vault modification (to infer social identity at the community level), and the composition and context of graves and grave goods (to access interindividual social identity relationships) during the Middle Horizon to Late Intermediate Period transition. Their findings indicate that biological diversity diminished (i.e., genetic homogeneity increased), isotopic diversity decreased (i.e., migration and paleomobility decreased), cranial modification homogenized, and there was a reduction in the range of individual markers of identity in mortuary contexts from the Middle Horizon to Late Intermediate Period. Torres-Rouff and Knudson note that their analyses allow them to identify broad changes in identity formation and presentation at the community level while also better understanding the complex intersections of identity that occur at the level of the individual. In constructing their analyses to incorporate evidence for identity at multiple scales, Torres-Rouff and Knudson (2017) provide a powerful example of an effective intersectional model-they are able to explore broad, systemic patterns occurring at the regional and community levels while also considering the multiplicity of identities that exist in a single individual and affect their experiences. Likewise, the Knudson and colleagues (2020) chapter provides examples of how bioarchaeologists might approach the issue of detecting systems of power in past populations using multiple lines of evidence from the archaeological record. For instance, the authors argue that variation in mortuary artifacts, strontium isotope values, and cranial trauma between the Solcor Plaza and Solcor-3 cemeteries reveals how structurallevel inequalities manifested in the daily experiences and differential access to trade and exchange networks available to certain groups during the Middle Horizon (500-1100 A.D.) in San Pedro de Atacama.

Third, a study by Yaussy (2019) applies intersectionality in her study of health outcomes in four skeletal samples from industrial-era England. Yaussy investigates how sex and socioeconomic status affect patterns of frailty (i.e., differential susceptibility to disease and death among members of a population; Vaupel et al. 1979) and mortality at the population level. Physiological indicators of stress differentially affected individuals occupying different intersectional positions or domains, underscoring the value of analyses that capture interactions among identity categories. For example, in her analyses of cribra orbitalia presence, Yaussy found that cribrotic lesions were associated with the intersection of socioeconomic status and sex, such that females of high socioeconomic status, specifically, were protected from the physiological insults responsible for the lesions (e.g., dietary deficiencies and parasitic infections during childhood). Yaussy explains that individual-level marginalizations (such as those associated with age, sex, and socioeconomic status) were coupled with systemic inequalities (such as the classist disparities in urban living conditions and sexist patterns of food distribution among low-status families) that compounded to produce patterns of frailty and mortality that may be obscured by traditional approaches. In the cribra orbitalia results, for instance, a conventional approach to the study of patterns of skeletal stress indicators would have recognized the significant association between cribra orbitalia and sex (i.e., cribrotic lesions were more 
common in male individuals) but would have missed the three-way relationship between cribra orbitalia presence, socioeconomic status, and sex. Consequently, the study by Yaussy demonstrates the potential for bioarchaeological studies to expose patterns of health and mortality and, perhaps more important, intersectional patterns of marginalization that existed in the past that were overlooked in previous historical and bioarchaeological studies. Additionally, given the close relationship between industrialera England and the concentration of intersectionality studies of living populations in Western, industrialized contexts (including the United Kingdom), the study by Yaussy (2019) also demonstrates the potential for bioarchaeological studies to meaningfully enter into interdisciplinary discussions of intersectionality and health by providing temporal depth and contextual details concerning the initial production and subsequent maintenance of systemic forms of oppression that are studied by social scientists in the present day.

Finally, a recent publication by Mant and colleagues (2021) has illustrated the wealth of biological, histomorphological, and sociocultural information that bioarchaeologists can pull from to examine the health consequences of intersectional identities in the past. The authors identify two case studies that exemplify an intersectional approach, even when the data were not originally collected with the goal of employing the concept of intersectionality in a study of health in the past. In the first case study, individualized historical records and patterns of trauma expose a complex history of addiction and abuse that ultimately produced the health outcomes observed in the examined individual's skeletal remains, including his many traumatic injuries and his unclaimed status in the Robert J. Terry Skeletal Anatomical Collection. In the second case study, the sociocultural context surrounding impoverished older women living in nineteenth-century London is considered in conjunction with trauma patterns on the skeleton of a female who was determined to be at least 46 years of age when she died while in the care of the Royal London Hospital. In both cases, trauma is considered a health outcome produced by the complex interaction of behavioral, biological, and sociocultural factors and processes operating at the individual and structural levels. The authors argue that "bone health and identity are inextricably linked" (Mant et al. 2021:590), and their work highlights the opportunities available to bioarchaeologists to perform intracategorical analyses and use multiple lines of evidence to examine how multiple, intersecting identities affected lived experiences and health outcomes in the past.

As recognized above, however, not all intersectional studies of health in anthropology (and, more specifically, in bioarchaeology) have explicitly used the term intersectionality. In its simplest form, intersectionality is a recognition of patterns of difference manifested at the individual level; the relationship of those patterns to multiple, coexisting axes of power and inequality; and how that relationship shapes the privilege and marginalization experienced by individuals and groups. As such, intersectionality has been leveraged by bioarchaeologists studying the outcomes of micro-level identities and macro-level inequalities for decades, despite not being explicitly named. For example, Torres-Rouff (2002) demonstrates the interrelated aspects of sex and ethnic identity in her study of cranial vault modification in the pre-Columbian Atacama. Specifically, Torres-Rouff argues that evidence from at least two archaeological sites suggests that the cultural practice of female exogamy influenced patterns of cranial modification in the Atacama, providing enduring evidence of the ways in which ethnic boundaries were maintained in individuals occupying particular intersectional positions (i.e., foreign women). Similarly, research conducted by de la Cova $(2010,2011,2012)$ examines disparities in skeletal indicators of disease and trauma between specific intersectional domains and connects these patterns of health and disease to structural violence and systemic inequities that were pervasive in nineteenth-century America. For instance, African American males born during the Reconstruction era exhibited higher frequencies of tuberculosis and treponematoses compared to their Euro-American counterparts, and this pattern is related to race-based discrimination and class-based differences in living conditions experienced by African American individuals who migrated to the North during the Reconstruction period (de la Cova 2011).

Other studies, such as the study of developmental stress in skeletal samples from Industrial London conducted by Hughes-Morey (2016), examine the intersections between sex and status in different settings, thus illustrating the context-dependent nature of identities, systemic oppression, and their effects on a variety of outcomes. In her study, Hughes-Morey argues that structural inequalities generated sex and class disparities in the early life experiences of the inhabitants of industrializing London. Particularly, the intersection of male sex and high socioeconomic status enabled wealthy males to survive to adulthood, despite relatively high frailty (evinced by relatively short tibiae and femora). In contrast, the intersection of low socioeconomic status and female sex had negative effects on both long bone length and risks of mortality, indicating the disparity between the health outcomes and lived experiences of multiply privileged and multiply marginalized individuals. It also bears mentioning that the study by Hughes-Morey (2016) recognizes the potential ramifications of intersecting 
identities in "middle groups" (i.e., individuals exhibiting combinations of advantaged and disadvantaged identities, such as high-status females or low-status males). The unique health outcomes of "middle groups" relative to multiply marginalized and multiply privileged individuals have been the subject of previous studies of intersectionality and health in living populations (Joe 2015; Sen and Iyer 2012). The focus of such studies is on the complex interaction between axes of advantage and disadvantage and the potential for such groups to leverage different aspects of their identities in different settings in unique ways that are not captured by analyses of multiply marginalized individuals. Importantly, these approaches to studying multiply marginalized groups, multiply privileged groups, and "middle groups" can be applied in bioarchaeological studies of pandemics in the past. The analytical methods used and interpretations produced by Hughes-Morey (2016) could feasibly be applied in a similarly designed study of the intersections of sex and socioeconomic status and their effects on the patterns of mortality associated with any number of pandemics in the past (e.g., tuberculosis, bubonic plague, leprosy).

The studies mentioned above, as well as other studies conducted in recent years (e.g., Agarwal 2012; Gowland 2017; Martin et al. 2010), illustrate a general inclination on behalf of bioarchaeologists to incorporate nuanced understandings of the intersections of social identities and forms of systemic oppression into our studies of lived experience, health, and disease in the past. Although many of the bioarchaeological studies cited above do not explicitly apply intersectionality theory, their research designs, findings, and interpretations demonstrate a vested interest in better understanding how multiple, intersecting identities-rather than distinct, independently operating identities-affect and are affected by the lived experiences of individuals and groups in the past. As described below, future work in paleopathology and paleoepidemiology might build upon such foundations by explicitly incorporating intersectionality into their research designs and analyses, which will generate novel, otherwise inaccessible insights into the effects of multiple, overlapping identities on patterns of disease in the past.

\section{Intersectionality and Past Pandemics}

\section{Previous bioarchaeological studies of past pandemics}

An examination of previous bioarchaeological studies of past pandemics reveals the outstanding work that has been done thus far in terms of investigating the impact of identity and inequality on health outcomes in the past, but it also illustrates the need for an intersectional perspective to understand unexplored and unexpected patterns of risk and health in the past. One of the best-known pandemics of the past was the Black Death (c. 1347-1351 A.D.), which killed 30\% to $60 \%$ of people in Europe and prompted widespread economic, political, and demographic change in European populations (DeWitte 2016). Much of the bioarchaeological work on the Black Death has relied on skeletal samples from cemeteries known to have accepted plague victims for burial, such as the East Smithfield cemetery in London (e.g., DeWitte 2010a, 2010b, 2012; Godde et al. 2020; Grainger et al. 2008). As the studies of East Smithfield illustrate, bioarchaeological studies of epidemic and pandemic burials have the potential to reveal the social responses to pandemic mortality, which could clarify not only how people responded to elevated mortality levels in the past (Castex 2008) but also how pandemics in the past exacerbated patterns of marginalization and inequality to disproportionately increase risk among the individuals at particular intersectional domains. For instance, previous bioarchaeological research on Black Death victims from London shows that older adults and people of all ages who were already in poor health before the epidemic were more likely to die than their younger or healthier peers (DeWitte and Wood 2008; Godde et al. 2020). A bioarchaeological study informed by an intersectional theoretical and analytical framework could further explore these patterns and determine if individuals at the intersections of particular axes of identity were at greater risk of negative health outcomes (such as earlier age at death) compared to other members of the same population. For example, although advanced age and compromised health status (frailty) have been implicated as significant factors influencing the risks of death during the Black Death in medieval London, an intersectional, intercategorical analysis of age, frailty, and other social or biological aspects of identity may expose unanticipated patterns of mortality risk previously overlooked by researchers employing traditional theoretical and analytical approaches.

Bioarchaeological studies of tuberculosis also exhibit the potential to reveal new or unexpected patterns of how privilege and marginalization affected health outcomes during epidemics in the past. In living populations, tuberculosis is associated with poverty and social stigmatization, and these associations likely existed in the past as well (Roberts 2011). Given the fact that it is capable of producing diagnostic bony lesions (Roberts and Buikstra 2003), tuberculosis is an example of a disease that can be included in bioarchaeological studies of intersectional health outcomes, 
even in the absence of supporting documentary or mortuary evidence. One paleoepidemiological study of tuberculosis has already revealed, for example, that survivorship for people with tuberculosis lesions varied by sex in early France (ca. 200-1500 A.D.) (Blondiaux et al. 2015). Future studies of tuberculosis in skeletal samples could employ an intersectional perspective to further clarify how different aspects of identity, marginalization, and health (e.g., sex or gender, socioeconomic status, migrant status, coinfection with leprosy) interacted to influence health outcomes associated with tuberculosis in the past. In these studies, researchers could pinpoint which social and biological categories individually affected the survivorship of individuals afflicted with tuberculosis in the past, yet also identify intersectional domains that experienced increased or decreased risks of mortality as a consequence of their position at the intersection of multiple marginalized or privileged identities within larger systems of power and oppression.

\section{Quantitative intersectional methods}

As intersectional approaches gain traction in anthropology and other social science disciplinesparticularly in disciplines that study health and disease-it becomes increasingly apparent that bioarchaeologists may have avoided relational approaches for methodological reasons. The history of the field of paleopathology, specifically, is steeped in the interpretation of lesion or pathology frequencies, occasionally divided by social or biological categories (such as sex or socioeconomic status) that are relevant to the research question of the given project or study. However, these categories are almost always examined in isolation, rather than in conjunction. As bioarchaeology tentatively engages with intersectional approaches and research frameworks, it is important to consider the suitability of analytical methods that are used to explore the intersections of dimensions of social difference and identity in modern or past populations. For instance, public health studies on modern populations have revealed that approaches that focus on a single category of difference (such as gender) will inevitably overlook or obfuscate the effects of multiple marginalizations (Bauer 2014; Bowleg 2012). Intersectional analyses of health and disease frequently examine the nonadditive effects of social and biological factors or categories (such as age, gender, race, and class) to evaluate the potential for factors to interact multiplicatively and thus synergistically enhance the negative effects that are produced by any of the factors or categories in isolation. Likewise, bioarchaeological analyses have already yielded (perhaps surprising) results regarding the existence of multiple mutually constitutive identities and oppressive structural processes and their effects on health and disease in the past (e.g., Yaussy 2019). To encourage and facilitate the use of intersectionality in empirical studies of health and disease in the past, a series of statistical approaches and mathematical models are provided below, with examples from recent social science scholarship that have successfully employed each method.

\section{Factorial analysis of variance}

A two- or three-way analysis of variance (ANOVA), also known as a factorial ANOVA, is one way to acknowledge the effects of independent variables on a continuous dependent variable while simultaneously considering the emergent effects that occur when two or more of those variables interact. In studies of health in past or present populations, such an analysis could elucidate how multiple social or biological aspects of identity influence the health outcome of interest, whatever it may be. The main requirements of a factorial ANOVA include one dependent variable that is measured at the continuous level (e.g., stature, age) and two or more independent variables that are divided into two or more categorical groups (e.g., gender, sex, ethnicity, occupation). One drawback of the factorial ANOVA in an intersectional study is the fact that the independent variables-also known as "factors," hence the name of the model-must be categorical, meaning the groups being included in the analysis must be discrete and independent. As such, a two- or three-way ANOVA would be unsuitable in intersectional analyses that aim to investigate the effects of fluid variables that resist classification into discrete categories. However, current methods in bioarchaeology often (arguably problematically) assign categorical labels to various aspects of identity (e.g., sex, status, age), meaning this issue only pertains to those studies attempting to avoid the limitations of categorical data. A second noteworthy limitation of factorial designs involves the number of categorical factors-in this case, identities-that can be included in a given analysis, since statistical power (i.e., the probability of a test of finding an effect if there is an effect to be found) decreases as the number of factors increases. This limitation can be particularly problematic in bioarchaeological studies, given the small sample sizes typically involved when working with skeletal data.

Bioarchaeological studies of health and disease in the past can use factorial ANOVA to measure a number of health outcomes (e.g., long bone length or stature, age at death) and compare those to identity categories accessible via skeletal or archaeological evidence (e.g., sex, socioeconomic status, frailty level or disease status, ability or impairment status). For instance, in a study of scalping victims from the site of 
the Crow Creek massacre in South Dakota (ca. 1325 A.D.), Kendell (2011) found that the interaction between the age and sex categories of the victims had an effect on the breadth of cuts made to the frontal bone during the scalping process. In this analysis, the dependent variable was cut breadth, whereas the independent variables were age (divided into categories of young, middle-aged, and older adults) and sex (divided into categories of male and female). Subsequent tests to determine the nature of the relationship among cut breadth, age, and sex revealed a significant negative relationship between cut breadth and age in male scalping victims but not female scalping victims. These results indicate that slightly different approaches to scalp removal were used for young and middle-aged males compared to older males and females of all ages. The author posited that this relationship was related to the prestige gained by an attacker who obtained the scalp of a "warrior" (i.e., a young, healthy male) versus the scalp of an older male or female individual. Although not explicitly intersectional, the research conducted by Kendell exemplifies a bioarchaeological application of factorial ANOVA to examine how intersecting identities-particularly age and sexinfluenced a health outcome that could be observed and measured in human skeletal remains.

\section{Logistic regression}

A second analytical method frequently used in intersectional studies of health is logistic regression. Logistic regression attempts to predict a dependent variable (e.g., the odds of one outcome or another outcome) based on one or more independent predictor variables that are included in the model. These predictor variables can be categorical (e.g., sex) or continuous (e.g., long bone lengths), meaning that a wide variety of biological and social factors can be included in the analysis. Logistic regression differs slightly from linear regression in that linear regression uses a continuous dependent variable rather than the dichotomous or polytomous (i.e., a categorical variable with more than two categories) dependent variables used in binomial and multinomial logistic regression, respectively. Linear regression models have also been used in intersectional studies of health in conjunction with other analytical techniques (e.g., Seng et al. 2012), but logistic regression is typically favored in studies of health when the dependent variable can be conveniently parsed into discrete categories (e.g., fair or poor health). For example, one bioarchaeological study of a past pandemic that uses binomial logistic regression includes Godde and colleagues' (2020) analysis of whether predictor variables like frailty, sex, or age at death affected the odds of dying of the Black Death (i.e., the dependent variable) in medieval London. In their analysis of frailty, for instance, the authors found that individuals with one or more skeletal indicators of frailty had a 3.7-fold increase in the odds of dying of the Black Death, suggesting that mortality during the Black Death was selective with respect to frailty.

Importantly, intersectional studies of health in modern populations have begun incorporating both additive (or unitary) and multiplicative approaches to better understand both the individual effects of factors of interest on the outcome of interest and the intersecting effects of the factors on the outcome of interest (Bauer 2014). In other words, combining the additive and multiplicative regression models allows researchers to establish whether statistical interactions (i.e., intersections) contribute to explanations of variability in health beyond that of the main effects (i.e., individual factors) alone. As a result, biological and social factors of interest can be considered separately (e.g., how age affects the odds of being obese) or in conjunction (e.g., how age and sex interact to affect the odds of being obese). A study by Veenstra (2011) uses this two-stage analytical strategy to investigate health outcomes associated with the intersections among race, gender, class, and sexual orientation. First, Veenstra uses additive regression models to assess how the independent identity variables affected self-rated health (fair vs. poor) in a Canadian sample. Second, Veenstra introduces cross-product terms (i.e., two- and three-way interaction terms) to the additive model to assess the effects of intersecting identities on self-rated health (i.e., multiplicative models). His findings - that several identity categories exhibited main effects; that gender, race, and sexual orientation each exhibit significant two-way interactions with class; and that gender exhibited a two-way interaction with raceindicate that poor self-rated health outcomes are associated with both independent identity categories (such as Indigeneity and bisexual sexual orientation) and intersectional domains (such as poor homosexuals). In sum, the two-stage approach combining additive and multiplicative modeling employed by Veenstra (2011) supports the use of logistic regression as an analytical strategy capable of exposing the independent and intersecting effects of identity categories on health. Additional examples of how logistic regression analysis can be used in conjunction with an intersectional perspective to investigate complex patterns in health include studies by Hinze and colleagues (2012) and Marcellin and colleagues (2013). Although bioarchaeological studies cannot access some of the self-rated or self-reported health outcomes addressed in studies of living populations, the quantitative methods employed by scholars in public health and epidemiology are still applicable to the social and biological categories accessible to paleopathologists and paleoepidemiologists. The multilevel models described by Veenstra (2011) and others offer bioarchaeologists the 
opportunity to expand upon the binomial logistic regression analyses conducted by scholars like Godde and colleagues (2020) to explicitly investigate the potential for intersectional domains to exert a significant effect on measured health outcomes in the past.

\section{Hierarchical log-linear analysis}

A third analytical technique that poses promise for intersectional studies of past pandemics is hierarchical log-linear analysis. Most generally, log-linear analysis is used to understand associations between two or more categorical variables. However, given that a chisquare test for association is more commonly performed to determine if there is a relationship between two categorical variables, log-linear analysis is typically only employed when three or more categorical variables are being included in the model. Thus, the value of a log-linear model is the opportunity to understand if a third categorical variable affects a twoway association previously exposed by cross-tabulation (i.e., understand if an association exists among all three variables) (Sloane and Morgan 1996). As seen in factorial ANOVA and logistic regression, log-linear analysis is capable of examining the main effects of the variables independent of each other, as well as higherorder interactions (e.g., two-way interactions, threeway interactions). Hierarchical log-linear analysis, specifically, assists the researcher in identifying the most parsimonious, unsaturated model (i.e., the model that combines the fewest main effects and interaction terms yet best accounts for most of the variance in the data). In terms of intersectional studies of health, hierarchical log-linear analysis identifies the intersections of two or more identities or health outcomes, which can then be further scrutinized to determine the intersectional domains or groups most affected by the association. Therein, however, lies the greatest shortcoming of hierarchical log-linear analysis: determining the direction of any intersectional associations. Hierarchical log-linear analysis is, in its simplest form, a model selection procedure. As such, it can identify significant associations, but it cannot determine the nature of the association. For example, hierarchical log-linear analysis could identify an association between gender and heart disease, yet it would not clarify whether men or women are at greater risk of heart disease. Thus, for hierarchical log-linear analysis to be incorporated into studies of health and the intersectional associations among identity variables, it must be paired with appropriate crosstabulation tables to investigate the nature of the associations identified by the log-linear model.

Examples of studies using hierarchical log-linear analysis to identify associations among health and other contextual factors exist within bioarchaeology (Yaussy 2019; Yaussy and DeWitte 2018; Yaussy et al.
2016). Although only one study explicitly addresses the implications of the results in light of intersectionality (Yaussy 2019), the findings of the other two studies still lend themselves to intersectional interpretations. For example, in their study of adult famine victims from medieval London, Yaussy and colleagues (2016) used hierarchical log-linear analysis to evaluate the associations among age at death, burial type (famine vs. attritional), sex (male vs. female), and frailty (evinced by the presence or absence of three skeletal indicators of stress). Among other two- and three-way associations, the hierarchical log-linear results indicated a significant four-way association among burial type, sex, age at death, and periosteal new bone formation. Subsequent chi-square tests indicated that periosteal lesions were more common in individuals interred in attritional burials (i.e., under normal mortality conditions, rather than the conditions that exist in the context of a famine), males, and middle-aged individuals (i.e., individuals who died between 26 and 45 years of age). Although not originally interpreted in light of intersectionality theory, the results of the study indicate the existence of intersections among identity categories (e.g., adult males) and health variables (e.g., risk of death during a famine, chances of surviving trauma or infection capable of eliciting an osteogenic response) that would not have been detected by conventional statistical approaches.

\section{Conclusions and Future Directions}

Despite - or perhaps because of-its "definitional dilemmas" (Collins 2015), intersectionality has become a widely applied theoretical and analytical framework within the social sciences and particularly in studies of health and disease. As discussed in the first section of this article, intersectionality recognizes "the interaction of multiple identities and experiences of exclusion and subordination" (Davis 2009:68), and studies of intersectionality seek to understand the production and maintenance of these systems of oppression and inequality, as well as the measurable positive and negative outcomes that they generate (e.g., physical and mental health, resource access, employment opportunities). In the examples of research studies provided in the second section of this article, intersectionality studies of health in living populations investigate the nonadditive nature of factors like age, gender, race, and class to expose how various aspects of identity and inequality can multiplicatively affect negative health outcomes in marginalized individuals and groups. Similarly, bioarchaeology is uniquely situated to contribute to discussions of how intersectionality affects health in a variety of settings and circumstances across time and space, illustrating the contextual nature of 
intersectional relationships and outcomes. To promote the application of intersectional techniques and interpretations in bioarchaeological studies of past pandemics, the second section of this article reviewed examples of successful intersectionality research projects in sociology, public health, and epidemiology, and the third section offered examples of intersectional research in bioarchaeology and presented potential quantitative methodologies that may be applicable to the study of disease in the past. Bioarchaeological studies interested in producing nuanced understandings of health and disease in the past must acknowledge the potential for multiple aspects of identity to intersect and interact with systems of oppression to produce complex patterns of disease risk unexplored by unidimensional analyses utilized in the field thus far. With the incorporation of quantitative methodologies oriented at exposing interactions and the effects of intersectional domains, studies of past pandemics can begin to identify and assess the patterns of health outcomes produced by the complex relationships among categories of identity and structural inequalities in the past.

It should be noted that the list of quantitative methods provided in the third section of this article is far from exhaustive (see, for example, the suggestions regarding intersectional approaches to the study of population health made by Bauer and Scheim 2019a, 2019b; Scheim and Bauer 2019). The statistical methods and mathematical models provided are a subset of those employed by scholars studying health and disease in living populations and were selected for further consideration as analytical techniques that could relatively painlessly be incorporated into bioarchaeological studies, particularly those of past pandemics. However, it is important to recognize that analytical approaches must arise from the research questions being asked (rather than vice versa) and the above list need not limit the methods of analysis adopted by bioarchaeologists engaging with intersectionality. On the contrary, the bioarchaeological studies of intersectionality discussed in this article are tremendous examples of the diversity of approaches that can be used to explore intersectionality in the past. TorresRouff and Knudson (2017), in particular, describe a multiscalar approach to individual, community, and regional identities that tracks change over time in the systemic processes and individual identities that produce variation in lived experiences of individuals and groups. A similar multiscalar approach could feasibly be applied to bioarchaeological studies of pandemics in the past and would broaden the methodological scope of paleoepidemiological studies in the future.

In addition to expanding the use of underutilized quantitative approaches, future intersectional studies in bioarchaeology may consider incorporating other recent methodological innovations into their research designs as well. As illustrated by the Torres-Rouff and Knudson (2017) example provided above, isotopic analyses could allow paleopathologists to examine aspects of identity that are typically inaccessible via conventional methods, including paleomobility (migration) and geographic region of origin. Likewise, recent advances in the estimation of age at death (Boldsen et al. 2002) enable bioarchaeologists to capture patterns of health at late adult ages (beyond the open-ended terminal age categories produced by conventional methods), facilitating the study of agerelated experiences across the life course. Finally, there is untapped potential in paleoepidemiological studies of disease ecology, which could use a combination of ancient DNA analyses and paleoproteomics to assess aspects of identity associated with disease susceptibility, health status, pathogen and host coevolution, and pathogen load. For example, it is now possible to examine coinfection with two or more pathogens in the past (Devault et al. 2014; Warinner et al. 2014), which could allow researchers to examine the intersection of multiple social identity categories, structural inequality, and the risk of coinfection during past epidemics and pandemics.

Importantly, a major critique of intersectional approaches in bioarchaeology stems from the foundational goals of intersectionality itself. As initially articulated by Black scholar-activists, intersectionality fundamentally explores the causes and effects of race/racism and sex/sexism at the individual and societal levels. Although it is possible to explore ascribed or self-identified axes of inequality like race through qualitative and quantitative analyses of living populations, this line of inquiry is largely unavailable to biological anthropologists who work with skeletal remains. Indeed, this review emphasizes the limitations of intersectional investigations in bioarchaeology, given that some individual identity categories and larger structural forces (like race and racism) may be inaccessible or inapplicable in many of our studies. However, as mentioned previously, the concept of multiple, interlocking oppressions affecting patterns of frailty and mortality in past populations remains pertinent to bioarchaeological research and is worth consideration in the future.

Last, in accordance with the overarching goals of intersectionality scholarship, future bioarchaeological studies of intersectionality have the potential to contribute to social justice projects by producing scholarship that leads to social change. Intersectionality and feminist theorizing in general are closely linked with social activism and social justice movements (Franklin 2001). Bioarchaeological studies, in particular, have 
the capacity to confront the normalization of structural inequality by adding contextual and temporal depth to intersectionality research conducted on living populations. The interpretations of bioarchaeological data and analyses can clarify how systemic forms of oppression were initially constructed and perpetuated in the past and thus can be challenged and dismantled in the present.

\section{Acknowledgments}

I extend my sincere appreciation to Gwen Robbins Schug and Siân Halcrow for inviting me to contribute to this special issue. I also thank Sharon DeWitte for her encouragement and thoughtful suggestions on previous drafts of this article. Finally, and perhaps most important, my sincere thanks goes to three anonymous reviewers for their comments and suggestions, which dramatically improved the quality of this manuscript.

\section{Further Reading}

DeWitte, Sharon N., and Samantha L. Yaussy. 2020. Bioarchaeological applications of intersectionality. In Theoretical Approaches in Bioarchaeology, edited by Colleen M. Cheverko, Julia R. Prince-Buitenhuys, and Mark Hubbe. Routledge, London, pp. 45-58.

Hankivsky, Olena. 2014. Intersectionality 101. Institute for Intersectionality Research and Policy, Simon Fraser University, Burnaby, British Columbia, pp. 1-34.

Rouhani, Setareh. 2014. Intersectionality-Informed Quantitative Research: A Primer. Institute for Intersectionality Research and Policy, Simon Fraser University, Burnaby, British Columbia, pp. 1-16.

\section{References Cited}

Agarwal, Sabrina C. 2012. The past of sex, gender, and health: Bioarchaeology of the aging skeleton. American Anthropologist 114(2):322-335. DOI: 10.1111/j.1548-1433.2012.01428.x.

Anzaldúa, Gloria. 1987. Borderlands/La Frontera: The New Mestiza. Aunt Lute Book Company, San Francisco.

Arnold, Emily A., Gregory M. Rebchook, and Susan M. Kegeles. 2014. 'Triply cursed': Racism, homophobia and HIV-related stigma are barriers to regular HIV testing, treatment adherence and disclosure among young Black gay men. Culture, Health \& Sexuality 16(6):710-722. DOI: 10.1080/13691058.2014.905706.

Baig, Arshiya A., Fanny Y. Lopez, Rachel H. DeMeester, Justin L. Jia, Monica E. Peek, and Monica B. Vela. 2016. Addressing barriers to shared decision making among Latino LGBTQ patients and healthcare providers in clinical settings. $L G B T$ Health 3(5):335-341. DOI: 10.1089/lgbt.2016.0014.

Bauer, Greta R. 2014. Incorporating intersectionality theory into population health research methodology: Challenges and the potential to advance health equity. Social Science \& Medicine 110:10-17. DOI: 10.1016/j.socscimed.2014.03.022.
Bauer, Greta R., and Ayden I. Scheim. 2019a. Advancing quantitative intersectionality research methods: Intracategorical and intercategorical approaches to shared and differential constructs. Social Science \& Medicine 226:260-262. DOI: 10.1016/j .socscimed.2019.03.018.

Bauer, Greta R., and Ayden I. Scheim. 2019b. Methods for analytic intercategorical intersectionality in quantitative research: Discrimination as a mediator of health inequalities. Social Science \& Medicine 226:236-245. DOI: 10.1016/j.socscimed.2018 .12 .015 .

Bhopal, Kalwant. 2020. Confronting White privilege: The importance of intersectionality in the sociology of education. British Journal of Sociology of Education 41(6):807-816. DOI: 10.1080 /01425692.2020.1755224.

Blondiaux, Joël, Amélie de Broucker, Thomas Colard, Azizul Haque, and Stephan Naji. 2015. Tuberculosis and survival in past populations: A paleo-epidemiological appraisal. Tuberculosis 95 (S1):S93-S100. DOI: 10.1016/j.tube.2015.02.002.

Boldsen, Jepser L., George R. Milner, Lyle W. Konigsberg, and James W. Wood. 2002. Transition analysis: A new method for estimating age from skeletons. In Paleodemography: Age Distributions from Skeletal Samples, edited by Robert D. Hoppa and James W. Vaupel. Cambridge University Press, Cambridge, pp. 73-106.

Bowleg, Lisa. 2008. When Black + lesbian + woman $\neq$ Black lesbian woman: The methodological challenges of qualitative and quantitative intersectionality research. Sex Roles 59(5-6): 312-325. DOI: 10.1007/s11199-008-9400-z.

Bowleg, Lisa. 2012. The problem with the phrase women and minorities: Intersectionality-an important theoretical framework for public health. American Journal of Public Health 102(7):1267-1273. DOI: 10.2105/AJPH.2012.300750.

Bowleg, Lisa. 2020. We're not all in this together: On COVID-19, intersectionality, and structural inequality. American Journal of Public Health 110:917. DOI: 10.2105/AJPH.2020.305766.

Bridges, Khiara. 2011. Reproducing Race: An Ethnography of Pregnancy as a Site of Racialization. University of California Press, Oakland.

Byrnes, Jennifer F. 2017. Injuries, impairment, and intersecting identities: The poor in Buffalo, NY 1851-1913. In Bioarchaeology of Impairment and Disability: Theoretical, Ethnohistorical, and Methodological Perspectives, edited by Jennifer F. Byrnes and Jennifer L. Muller. Bioarchaeology and Social Theory. Springer International Publishing, Cham, Switzerland, pp. 201-222.

Castex, Dominique. 2008. Identification and interpretation of historical cemeteries linked to epidemics. In Paleomicrobiology: Past Human Infections, edited by Didier Raoult and Michel Drancourt. Springer-Verlag, Berlin, pp. 23-48.

Chan, Christian D., and Lionel C. Howard. 2018. When queerness meets intersectional thinking: Revolutionizing parallels, histories, and contestations. Journal of Homosexuality: 67 (3):346366. DOI: $10.1080 / 00918369.2018 .1530882$.

Chenery, Carolyn, Gundula Müldner, Jane Evans, Hella Eckardt, and Mary Lewis. 2010. Strontium and stable isotope evidence for diet and mobility in Roman Gloucester, UK. Journal of Archaeological Science 37(1):150-163. DOI: 10.1016/j.jas.2009.09.025.

Cho, Sumi, Kimberlé Williams Crenshaw, and Leslie McCall. 2013. Toward a field of intersectionality studies: Theory, applications, and praxis. Signs: Journal of Women in Culture and Society 38(4):785-810. DOI: 10.1086/669608.

Choo, Hae Yeon, and Myra Marx Ferree. 2010. Practicing intersectionality in sociological research: A critical analysis of inclusions, interactions, and institutions in the study of inequalities. Sociological Theory 28(2):129-149. DOI: 10.1111/j.1467-9558.2010 .01370.x. 
Christensen, Ann-Dorte, and Sune Qvotrup Jensen. 2012. Doing intersectional analysis: Methodological implications for qualitative research. NORA-Nordic Journal of Feminist and Gender Research 20(2):109-125. DOI: 10.1080/08038740.2012 .673505 .

Cole, Elizabeth R. 2009. Intersectionality and research in psychology. American Psychologist 64(3):170-180. DOI: 10.1037 /a0014564.

Collins, Pamela Y., Hella von Unger, and Adria Armbrister. 2008. Church ladies, good girls, and locas: Stigma and the intersection of gender, ethnicity, mental illness, and sexuality in relation to HIV risk. Social Science \& Medicine 67(3):389-397. DOI: 10.1016/j.socscimed.2008.03.013.

Collins, Patricia Hill. 2015. Intersectionality's definitional dilemmas. Annual Review of Sociology 41(1):1-20. DOI: 10.1146 /annurev-soc-073014-112142.

Collins, Patricia Hill, and Sirma Bilge. 2016. Intersectionality. John Wiley \& Sons, Hoboken, NJ.

Combahee River Collective. 1977. A Black feminist statement. In The Black Feminist Reader (2000), edited by Joy James and T. Denean Sharpley-Whiting. Blackwell, Malden, MA, pp. 261-270.

Covarrubias, Alejandro. 2011. Quantitative intersectionality: A critical race analysis of the Chicana/o educational pipeline. Journal of Latinos and Education 10(2):86-105. DOI: 10.1080 /15348431.2011.556519.

Crenshaw, Kimberlé Williams. 1989. Demarginalizing the intersection of race and sex: A Black feminist critique of antidiscrimination doctrine, feminist theory and antiracist politics. University of Chicago Legal Forum 1 (Article 8):139-167.

Crenshaw, Kimberlé Williams. 1991. Mapping the margins: Intersectionality, identity politics, and violence against women of color. Stanford Law Review 43(6):1241-1299.

Davis, Angela Yvonne. 1983. Women, Race, and Class. Vintage, New York.

Davis, Kathy. 2009. Intersectionality as buzzword: A sociology of science perspective on what makes a feminist theory successful. Feminist Theory 9:67-85. DOI: 10.1177/1464700108086364.

de la Cova, Carlina. 2010. Cultural patterns of trauma among 19thcentury-born males in cadaver collections. American Anthropologist 112(4):589-606. DOI: 10.1111/j.1548-1433.2010.01278.x.

de la Cova, Carlina. 2011. Race, health, and disease in 19thcentury-born males. American Journal of Physical Anthropology 144(4):526-537. DOI: 10.1002/ajpa.21434.

de la Cova, Carlina. 2012. Patterns of trauma and violence in 19thcentury-born African American and Euro-American females. International Journal of Paleopathology 2(2-3):61-68. DOI: 10 .1016/j.ijpp.2012.09.009.

Dent, Sophia C. 2017. Interindividual differences in embodied marginalization: Osteological and stable isotope analyses of antebellum enslaved individuals. American Journal of Human Biology 29(4):e23021. DOI: 10.1002/ajhb.23021.

Devault, Alison M., Kevin McLoughlin, Crystal Jaing, Shea Gardner, Teresita M. Porter, Jacob M. Enk, et al. 2014. Ancient pathogen DNA in archaeological samples detected with a Microbial Detection Array. Scientific Reports 4:4245. DOI: 10 .1038/srep04245.

DeWitte, Sharon N. 2010a. Age patterns of mortality during the Black Death in London, A.D. 1349-1350. Journal of Archaeological Science 37(12):3394-3400. DOI: 10.1016/j.jas.2010.08.006.

DeWitte, Sharon N. 2010b. Sex differentials in frailty in medieval England. American Journal of Physical Anthropology 143(2):285-297. DOI: 10.1002/ajpa.21316.

DeWitte, Sharon N. 2012. Sex differences in periodontal disease in catastrophic and attritional assemblages from medieval London. American Journal of Physical Anthropology 149:405416. DOI: 10.1002/ajpa.22138.
DeWitte, Sharon N. 2016. Archaeological evidence of epidemics can inform future epidemics. Annual Review of Anthropology 45(1):63-77. DOI: 10.1146/annurev-anthro-102215-095929.

DeWitte, Sharon N., and James W. Wood. 2008. Selectivity of Black Death mortality with respect to preexisting health. Proceedings of the National Academy of Sciences of the United States of America 105(5):1436-1441. DOI: 10.1073/pnas.07054 60105.

Di Stasio, Valentina, and Edvard N. Larsen. 2020. The racialized and gendered workplace: Applying an intersectional lens to a field experiment on hiring discrimination in five European labor markets. Social Psychology Quarterly 83(3):229-250. DOI: $10.1177 / 0190272520902994$.

Doyal, Lesley. 2009. Challenges in researching life with HIV/ AIDS: An intersectional analysis of Black African migrants in London. Culture, Health \& Sexuality 11(2):173-188. DOI: 10.1080 /13691050802560336.

Dubrow, Joshua Kjerulf. 2008. How can we account for intersectionality in quantitative analysis of survey data? Empirical illustration for Central and Eastern Europe. ASK: Research \& Methods 17(1):85-100.

Dworkin, Shari L. 2005. Who is epidemiologically fathomable in the HIV/AIDS epidemic? Gender, sexuality, and intersectionality in public health. Culture, Health \& Sexuality 7(6):615-623. DOI: 10.1080/13691050500100385.

Franklin, Maria. 2001. A Black feminist-inspired archaeology? Journal of Social Archaeology 1(1):108-125. DOI: 10.1177/146960 530100100108.

Freedman, Jane. 2016. Sexual and gender-based violence against refugee women: A hidden aspect of the refugee "crisis." Reproductive Health Matters 24(47):18-26. DOI: 10.1016/j.rhm.2016 .05 .003 .

Geller, Pamela L. 2017. The Bioarchaeology of Socio-Sexual LivesQueering Common Sense about Sex, Gender, and Sexuality. Springer, New York.

Gibb, James K., L. Zachary DuBois, Sarah Williams, Luseadra McKerracher, Robert-Paul Juster, and Jessica Fields. 2020. Sexual and gender minority health vulnerabilities during the COVID-19 health crisis. American Journal of Human Biology 32(5):e23499. DOI: 10.1002/ajhb.23499.

Giritli Nygren, Katarina, and Anna Olofsson. 2014. Intersectional approaches in health-risk research: A critical review. Sociology Compass 8(9):1112-1126. DOI: 10.1111/soc4.12176.

Gkiouleka, Anna, Tim Huijts, Jason Beckfield, and Clare Bambra. 2018. Understanding the micro and macro politics of health: Inequalities, intersectionality \& institutions-A research agenda. Social Science \& Medicine 200:92-98. DOI: 10.1016/j.socscimed 2018.01.025.

Godde, Kanya, Valerie Pasillas, and America Sanchez. 2020. Survival analysis of the Black Death: Social inequality of women and the perils of life and death in Medieval London. American Journal of Physical Anthropology 173:168-178. DOI: 10.1002 /ajpa.24081.

Gowland, Rebecca. 2017. Growing old: Biographies of disability and care in later life. In New Developments in the Bioarchaeology of Care: Further Case Studies and Expanded Theory, edited by Lorna Tilley and Alecia A. Schrenk. Springer International, Cham, Switzerland, pp. 237-251.

Grainger, Ian, Duncan Hawkins, Lynne Cowal, and Richard Mikulski. 2008. The Black Death Cemetery, East Smithfield, London. MOLAS Monograph 43, Museum of London Archaeology Service, London.

Hancock, Ange-Marie. 2007. When multiplication doesn't equal quick addition: Examining intersectionality as a research paradigm. Perspectives on Politics 5(1):63-79. DOI: 10.1017 /S1537592707070065. 
Hancock, Ange-Marie. 2019. Empirical intersectionality: A tale of two approaches. In The Palgrave Handbook of Intersectionality in Public Policy, edited by Olena Hankivsky and Julia S. Jordan-Zachery. Springer, New York, pp. 95-132.

Hargrove, Taylor W. 2018. BMI trajectories in adulthood: The intersection of skin color, gender, and age among African Americans. Journal of Health and Social Behavior: 59(4):501519. DOI: $10.1177 / 0022146518802439$.

Hinze, Susan W., Jielu Lin, and Tanetta E. Andersson. 2012. Can we capture the intersections? Older Black women, education, and health. Women's Health Issues: Official Publication of the Jacobs Institute of Women's Health 22(1):e91-98. DOI: 10.1016/j .whi.2011.08.002.

hooks, bell. 1981. Ain't I a Woman: Black Women and Feminism. South End Press, Boston, MA.

Hughes-Morey, Gail. 2016. Interpreting adult stature in industrial London. American Journal of Physical Anthropology 159(1):126134. DOI: 10.1002/ajpa.22840.

Hunting, Gemma. 2014. Qualitative Intersectionality-Informed Research: A Primer. Institute for Intersectionality Research and Policy, Simon Fraser University, Burnaby, British Columbia, pp. 1-20.

Ilunga, Blandine B., Owen O. Eales, Tessa S. Marcus, Selma Smith, and Jannie F. Hugo. 2020. Interpreting Mamelodi community-oriented primary care data on tuberculosis loss to follow-up through the lens of intersectionality. African Journal of Primary Health Care \& Family Medicine 12(1):1-6. DOI: 10.4102/phcfm.v12i1.2081.

Iyer, A., G. Sen, and P. Ostlin. 2008. The intersections of gender and class in health status and health care. Global Public Health 3 (S1):13-24. DOI: 10.1080/17441690801892174.

Jackson, Fatimah L. C. 2003. Ethnogenetic layering: A novel approach to determining environmental health risks among children from three US regions. Journal of Children's Health 1(3):369-386. DOI: 10.3109/15417060390254355.

Jackson, Fatimah L. C. 2004. Human genetic variation and health: New assessment approaches based on ethnogenetic layering. British Medical Bulletin 69(1):215-235. DOI: 10.1093/bmb /ldh012.

Jackson, Fatimah L. C. 2008. Ethnogenetic layering (EL): An alternative to the traditional race model in human variation and health disparity studies. Annals of Human Biology 35(2):121144. DOI: $10.1080 / 03014460801941752$.

Jackson-Best, Fatimah. 2016. A narrative review of maternal depression research focusing on women of Caribbean descent in the diaspora and Caribbean women in the region. Journal of International Women's Studies 17(3):32-44.

Jackson-Best, Fatimah, and Nancy Edwards. 2018. Stigma and intersectionality: A systematic review of systematic reviews across HIV/AIDS, mental illness, and physical disability. BMC Public Health 18(1): 919. DOI: 10.1186/s12889-018-5861-3.

Jang, Sung Tae. 2018. The implications of intersectionality on southeast Asian female students' educational outcomes in the United States: A critical quantitative intersectionality analysis. American Educational Research Journal 55(6):1268-1306. DOI: 10.3102/0002831218777225.

Joe, William. 2015. Intersectional inequalities in immunization in India, 1992-93 to 2005-06: A progress assessment. Health Policy and Planning 30(4):407-422. DOI: 10.1093/heapol/czu023.

Jones, Katherine Castiello, Joya Misra, and K. McCurley. 2013. Intersectionality in Sociology. Sociologists for Women in Society. http://socwomen.org/wpcontent/uploads/swsfactsheet_intersectionality.pdf. Accessed December 18, 2020.

Kendell, Ashley. 2011. The Crow Creek Massacre: The Role of Sex in Native American Scalping Practices. M.A. thesis, California State University, Chico.
Kigozi, G., C. Heunis, P. Chikobvu, S. Botha, and D. Van Rensburg. 2017. Factors influencing treatment default among tuberculosis patients in a high burden province of South Africa. International Journal of Infectious Diseases 54:95-102. DOI: 10 .1016/j.ijid.2016.11.407.

King, Deborah K. 1988. Multiple jeopardy, multiple consciousness: The context of a Black feminist ideology. Signs: Journal of Women in Culture and Society 14(1):42-72.

Knudson, Kelly J., Christina Torres-Rouff, and Aliya R. Hoff. 2020. Intersectionality and the multiplicity of identities in the Andean past. In Bioarchaeology and Identity Revisited, edited by Kelly J. Knudson and Christopher M. Stojanowski. University Press of Florida, Gainesville, pp. 185-198.

Laster Pirtle, Whitney N. 2020. Racial capitalism: A fundamental cause of novel coronavirus (COVID-19) pandemic inequities in the United States. Health Education \& Behavior 47(4):504-508. DOI: 10.1177/1090198120922942.

Leach, Stephany, Mary Lewis, Carolyn Chenery, Gundula Müldner, and Hella Eckardt. 2009. Migration and diversity in Roman Britain: A multidisciplinary approach to the identification of immigrants in Roman York, England. American Journal of Physical Anthropology 140(3):546-561. DOI: 10.1002/ajpa.21104.

Liew, S. M., E. M. Khoo, B. K. Ho, Y. K. Lee, O. Mimi, M. Y. Fazlina, et al. 2015. Tuberculosis in Malaysia: Predictors of treatment outcomes in a national registry. International Journal of Tuberculosis and Lung Disease 19(7):764-771. DOI: 10.5588/ijtld.14.0767.

Lorde, Audre. 1984. Sister Outsider: Essays and Speeches. The Crossing Press, Berkeley, CA.

Mant, Madeleine, Carlina de la Cova, and Megan B. Brickley. 2021. Intersectionality and trauma analysis in bioarchaeology. American Journal of Physical Anthropology 174(4):583-594. DOI: 10.1002/ajpa.24226.

Marcellin, Roxanne L., Greta R. Bauer, and Ayden I. Scheim. 2013. Intersecting impacts of transphobia and racism on HIV risk among trans persons of colour in Ontario, Canada. Ethnicity and Inequalities in Health and Social Care 6(4):97-107. DOI: 10 .1108/EIHSC-09-2013-0017.

Martin, Debra L., Ryan P. Harrod, and Misty Fields. 2010. Beaten down and worked to the bone: Bioarchaeological investigations of women and violence in the ancient Southwest. Landscapes of Violence 1(1):1-9.

McCall, Leslie. 2001. Sources of racial wage inequality in metropolitan labor markets: Racial, ethnic, and gender differences. American Sociological Review 66(4):520-541. DOI: 10.2307/3088921.

McCall, Leslie. 2005. The complexity of intersectionality. Signs: Journal of Women in Culture and Society 30(3):1771-1800. DOI: $10.1086 / 426800$.

Merlo, Juan. 2018. Multilevel analysis of individual heterogeneity and discriminatory accuracy (MAIHDA) within an intersectional framework. Social Science \& Medicine 203:74-80. DOI: 10.1016/j.socscimed.2017.12.026.

Millett, Gregorio A., William L. Jeffries, John L. Peterson, David J. Malebranche, Tim Lane, Stephen A. Flores, et al. 2012. Common roots: A contextual review of HIV epidemics in Black men who have sex with men across the African diaspora. The Lancet 380(9839):411-423. DOI: 10.1016/S0140-6736(12)60722-3.

Misra, Joya, Celeste Vaughan Curington, and Venus Mary Green. 2020. Methods of intersectional research. Sociological Spectrum 41(1):9-20. DOI: 10.1080/02732173.2020.1791772.

Mitchell, Donald Jr., Charlana Y. Simmons, and Lindsay A. Greyerbiehl. 2014. Intersectionality \& Higher Education. Peter Lang, New York.

Montgomery, Janet. 2002. Lead and Strontium Isotope Compositions of Human Dental Tissues as an Indicator of Ancient Exposure and Population Dynamics. Ph.D. dissertation, University of Bradford, Bradford, UK. 
Moradi, Bonnie. 2017. (Re)focusing intersectionality: From social identities back to systems of oppression and privilege. In Handbook of Sexual Orientation and Gender Diversity in Counseling and Psychotherapy, edited by Kurt A. DeBord, Ann R. Fischer, Kathleen J. Bieschke, and Ruperto M. Perez. American Psychological Association, Washington, D.C., pp. 105-127.

Moradi, Bonnie, and Patrick R. Grzanka. 2017. Using intersectionality responsibly: Toward critical epistemology, structural analysis, and social justice activism. Journal of Counseling Psychology 64(5):500-513. DOI: 10.1037/cou0000203.

Müldner, Gundula, Carolyn Chenery, and Hella Eckardt. 2011. The 'Headless Romans': Multi-isotope investigations of an unusual burial ground from Roman Britain. Journal of Archaeological Science 38(2):280-290. DOI: 10.1016/j.jas.2010.09.003.

Muture, Bernard N., Margaret N. Keraka, Peter K. Kimuu, Ephantus W. Kabiru, Victor O. Ombeka, and Francis Oguya. 2011. Factors associated with default from treatment among tuberculosis patients in Nairobi province, Kenya: A case control study. BMC Public Health 11(1):696. DOI: 10.1186/1471-2458-11-696.

Nash, Jennifer C. 2008. Re-thinking intersectionality. Feminist Review 89(1):1-15. DOI: 10.1057/fr.2008.4.

Pager, Devah. 2003. The mark of a criminal record. American Journal of Sociology 108(5):937-975. DOI: 10.1086/374403.

Paik, Leslie. 2017. Critical perspectives on intersectionality and criminology: Introduction. Theoretical Criminology 21(1):4-10. DOI: $10.1177 / 1362480616677495$.

Patil, Vrushali. 2013. From patriarchy to intersectionality: A transnational feminist assessment of how far we've really come. Signs: Journal of Women in Culture and Society 38(4):847-867. DOI: $10.1086 / 669560$.

Purdie-Vaughns, Valerie, and Richard P. Eibach. 2008. Intersectional invisibility: The distinctive advantages and disadvantages of multiple subordinate-group identities. Sex Roles 59(5-6):377-391. DOI: 10.1007/s11199-008-9424-4.

Roberts, Charlotte A. 2011. The bioarchaeology of leprosy and tuberculosis: A comparative study of perceptions, stigma, diagnosis, and treatment. In Social Bioarchaeology, edited by Sabrina C. Agarwal and Bonnie A. Glencross. Wiley-Blackwell, Malden, MA, pp. 252-282.

Roberts, Charlotte A., and Jane E. Buikstra. 2003. The Bioarchaeology of Tuberculosis: A Global View on a Reemerging Disease. University Press of Florida, Gainesville.

Ryan, Nessa E., and Alison M. El Ayadi. 2020. A call for a genderresponsive, intersectional approach to address COVID-19. Global Public Health 15(9):1404-1412. DOI: 10.1080/17441692 .2020.1791214.

Scheim, Ayden I., and Greta R. Bauer. 2019. The intersectional discrimination index: Development and validation of measures of self-reported enacted and anticipated discrimination for intercategorical analysis. Social Science \& Medicine 226:225235. DOI: 10.1016/j.socscimed.2018.12.016.

Scott, Nicholas A., and Janet Siltanen. 2017. Intersectionality and quantitative methods: Assessing regression from a feminist perspective. International Journal of Social Research Methodology 20(4):373-385. DOI: 10.1080/13645579.2016.1201328.

de Seixas Maciel, Elvira Maria Godinho, Juliana de Souza Amancio, Daniel Barros de Castro, and José Ueleres Braga. 2018. Social determinants of pulmonary tuberculosis treatment non-adherence in Rio de Janeiro, Brazil. PLoS One 13(1):e0190578. DOI: 10.1371/journal.pone.0190578.

Sen, Gita, and Aditi Iyer. 2012. Who gains, who loses and how: Leveraging gender and class intersections to secure health entitlements. Social Science \& Medicine 74(11):1802-1811. DOI: 10 .1016/j.socscimed.2011.05.035.

Seng, Julia S., William D. Lopez, Mickey Sperlich, Lydia Hamama, and Caroline D. Reed Meldrum. 2012. Marginalized identities, discrimination burden, and mental health: Empirical exploration of an interpersonal-level approach to modeling intersectionality. Social Science \& Medicine 75(12):2437-2445. DOI: 10 .1016/j.socscimed.2012.09.023.

Sengupta, Shuddhabrata. 2006. I/me/mine-Intersectional identities as negotiated minefields. Signs: Journal of Women in Culture and Society 31(3):629-639. DOI: 10.1086/499318.

Shaw, Heidi, Janet Montgomery, Rebecca Redfern, Rebecca Gowland, and Jane Evans. 2016. Identifying migrants in Roman London using lead and strontium stable isotopes. Journal of Archaeological Science 66:57-68. DOI: 10.1016/j.jas.2015.12.001.

Sloane, Douglas, and S. Philip Morgan. 1996. An introduction to categorical data analysis. Annual Review of Sociology 22(1):351375. DOI: 10.1146/annurev.soc.22.1.351.

Spierings, Niels. 2012. The inclusion of quantitative techniques and diversity in the mainstream of feminist research. European Journal of Women's Studies 19(3):331-347. DOI: 10.1177/135050 6812443621.

Springer, Kristen W., Olena Hankivsky, and Lisa M. Bates. 2012. Gender and health: Relational, intersectional, and biosocial approaches. Social Science \& Medicine 74(11):1661-1666. DOI: 10 .1016/j.socscimed.2012.03.001.

Tan, Judy Y., Lucy J. Xu, Fanny Y. Lopez, Justin L. Jia, Mai T. Pho, Karen E. Kim, et al. 2016. Shared decision making among clinicians and Asian American and Pacific Islander sexual and gender minorities: An intersectional approach to address a critical care gap. LGBT Health 3(5):327-334. DOI: 10.1089/lgbt.2015.0143.

Tefera, Adai A., Jeanne M. Powers, and Gustavo E. Fischman. 2018. Intersectionality in Education: A Conceptual Aspiration and Research Imperative. SAGE, Los Angeles, CA.

Tola, Habteyes Hailu, Azar Tol, Davoud Shojaeizadeh, and Gholamreza Garmaroudi. 2015. Tuberculosis treatment nonadherence and lost to follow up among TB patients with or without HIV in developing countries: A systematic review. Iranian Journal of Public Health 44(1):1-11.

Torres-Rouff, Christina. 2002. Cranial vault modification and ethnicity in middle horizon San Pedro de Atacama, Chile. Current Anthropology 43(1):163-171. DOI: 10.1086/338290.

Torres-Rouff, Christina, and Kelly J. Knudson. 2017. Integrating identities: An innovative bioarchaeological and biogeochemical approach to analyzing the multiplicity of identities in the mortuary record. Current Anthropology 58(3):381-409. DOI: 10 $.1086 / 692026$.

Vaupel, James W., K. G. Manton, and E. Stallard. 1979. The impact of heterogeneity in individual frailty on the dynamics of mortality. Demography 16:439-454. DOI: 10.2307/2061224.

Veenstra, Gerry. 2011. Race, gender, class, and sexual orientation: intersecting axes of inequality and self-rated health in Canada. International Journal for Equity in Health 10(1):3. DOI: 10.1186 /1475-9276-10-3.

Verloo, Mieke. 2006. Multiple inequalities, intersectionality and the European Union. European Journal of Women's Studies 13(3):211-228. DOI: 10.1177/1350506806065753.

Viruell-Fuentes, Edna A., Patricia Y. Miranda, and Sawsan Abdulrahim. 2012. More than culture: Structural racism, intersectionality theory, and immigrant health. Social Science \& Medicine 75(12):2099-2106. DOI: 10.1016/j.socscimed.2011.12.037.

Walby, Sylvia. 2007. Complexity theory, systems theory, and multiple intersecting social inequalities. Philosophy of the Social Sciences 37(4):449-470. DOI: 10.1177/0048393107307663.

Warinner, Christina, João F. Matias Rodrigues, Rounak Vyas, Christian Trachsel, Natallia Shved, Jonas Grossmann, et al. 2014. Pathogens and host immunity in the ancient human oral cavity. Nature Genetics 46(4):336-344. DOI: 10.1038/ng.2906.

Watkins-Hayes, Celeste. 2014. Intersectionality and the sociology of HIV/AIDS: Past, present, and future research directions. 
Annual Review of Sociology 40:431-457. DOI: 10.1146/annurev -soc-071312-145621.

Wenham, Clare, Julia Smith, and Rosemary Morgan. 2020. COVID-19: The gendered impacts of the outbreak. The Lancet 395(10227):846-848. DOI: 10.1016/S0140-6736(20)30526-2.

Werbner, Pnina. 2013. Everyday multiculturalism: Theorising the difference between 'intersectionality' and 'multiple identities.' Ethnicities 13(4):401-419. DOI: 10.1177/1468796813483728.

Williams, Christine L. 1995. Still a Man's World: Men Who Do Women's Work. University of California Press, Oakland.

Wingfield, Adia Harvey. 2009. Racializing the glass escalator: Reconsidering men's experiences with women's work. Gender \& Society 23(1):5-26. DOI: 10.1177/0891243208323054.

Yaussy, Samantha L. 2019. The intersections of industrialization: Variation in skeletal indicators of frailty by age, sex, and socioeconomic status in 18th- and 19th-century England. American Journal of Physical Anthropology 170(1):116-130. DOI: 10.1002/ajpa.23881.

Yaussy, Samantha L., and Sharon N. DeWitte. 2018. Patterns of frailty in non-adults from medieval London. International Journal of Paleopathology 22:1-7. DOI: 10.1016/j.ijpp.2018.03.008.

Yaussy, Samantha L., Sharon N. DeWitte, and Rebecca C. Redfern. 2016. Frailty and famine: Patterns of mortality and physiological stress among victims of famine in medieval London. American Journal of Physical Anthropology 160(2):272-283. DOI: 10 .1002/ajpa.22954.

Zuckerman, Molly K., and John Crandall. 2019. Reconsidering sex and gender in relation to health and disease in bioarchaeology. Journal of Anthropological Archaeology 54:161-171. DOI: 10.1016/j.jaa.2019.04.001. 